\title{
Expressional Changes of Water Transport-related Molecules in the Efferent Ductules and Initial Segment of Mouse Treated with Bisphenol A-Containing Drinking Water for Two Generations
}

\author{
Su-Yong Han $^{1}$ and ${ }^{\dagger}$ Ki-Ho Lee ${ }^{2}$ \\ ${ }^{1}$ College of Liberal Arts and Sciences, Anyang University, Incheon 417-833, Republic of Korea \\ ${ }^{2}$ Department of Biochemistry and Molecular Biology, College of Medicine, Eulji University, \\ Daejeon 301-746, Republic of Korea
}

\begin{abstract}
Bisphenol A (BPA) is an estrogenic endocrine disrupter. However, depending on a way of treatment, the harmful effects of BPA have not been confirmed. Also, trans-generational effects of BPA on male reproduction are still controversial. Because the reabsorption of testicular fluid in the efferent ductules (ED) and initial segment (IS) is important for sperm maturation, the present study was designed to determine trans-generational effect of BPA administrated orally on expression of water transport-related molecules in the mouse ED and IS. Ethanol-dissolved BPA was diluted in water to be $100 \mathrm{ng}$ (low), 10 (medium), and $1 \mathrm{mg}$ water (high). BPA-containing water was provided for two generations. Expression of ion transporters and water channels in the ED and IS were measured by relative real-time PCR analysis. In the ED, BPA treatment caused expressional increases of carbonic anhydrase II, cystic fibrosis transmembrane regulator, $\mathrm{Na}^{+} / \mathrm{K}^{+} \mathrm{ATPase}$ $\alpha 1$ subunit, and aquaporin (AQP) 1. No change of $\mathrm{Na}^{+} / \mathrm{H}^{+}$exchange (NHE) 3 expression was detected. BPA treatment at medium dose resulted in an increase of AQP9 expression. In the IS, the highest expressional levels of all molecules tested were observed in medium-dose BPA treatment. Generally, high-dose BPA treatment resulted in a decrease or no change of gene expression. Fluctuation of NHE3 gene expression by BPA treatment at different concentrations was detected. These findings suggest that trans-generational exposure to BPA, even at low dose, could affect gene expression of water-transport related molecules. However, such effects of BPA would be differentially occurred in the ED and IS.
\end{abstract}

Key words : Efferent ductules, Initial segment, Water transport, Bisphenol A, Male reproduction

\section{INTRODUCTION}

Bisphenol A (BPA) is an environmental endocrine disrupter which possesses estrogenic activity (Rubin, 2011). Detrimental effects of BPA on health and reproduction have been extensively described (Rubin, 2011; Wong \& Cheng, 2011). The unfavorable effects of BPA on male reproduction include decreases of sperm production and quality (vom Saal et al., 1998), reduction of epididymal weight
(Gupta, 2000), and suppression of expression of testicular steroidogenic enzymes (Nanjappa et al., 2012). It has been widely considered that BPA can exert its activity through classical estrogen receptor (ER) signaling pathway, with binding to the estrogen receptor element site in the target DNA (Sheeler et al., 2000). However, a growing body of evidence indicates that BPA can elicit cellular responses via non-classical estrogen triggered mechanisms (AlonsoMagdelena et al., 2012).

\footnotetext{
Manuscript received 5 September 2013, Received in revised form 9 September 2013, Accepted 14 September 2013

${ }^{\dagger}$ Corresponding Author : Ki-Ho Lee, Department of Biochemistry and Molecular Biology and Medical Sciences Research Institute, Eulji University, Daejeon 301-746, Republic of Korea. Tel. : +82-42-259-1643, Fax : +82-42-259-1649, E-mail : kiholee@eulji.ac.kr

This is an Open Access article distributed under the terms of the Creative Commons Attribution Non-Commercial License(http://creativecommons.org/ licenses/by-nc/3.0) which permits unrestricted non-commercial use, distribution, and reproduction in any medium, provided the original work is properly cited.
} 
BPA is commonly found in daily consuming products, including food and beverage containers, baby bottles, and an additive in other plastics. Also, BPA is a component of dental sealants, coating of CDs and DVDs, and other electronic materials (Welshons et al., 2006). Thus, human exposure to BPA can be achieved through ingestion, inhalation, and direct skin contact, and ingestion is considered the major route of BPA consumption in human (Vandenberg et al., 2010). However, negative effects of BPA on the reproduction have been revealed from subcutaneous or internal injection into experimental animals. In addition, a safe dose of BPA for human health has not been settled down because many studies have demonstrated BPA-related effects at very low doses, considered as a safe dose of BPA acceptable for daily intake by the U.S. Environmental Protection Agency (Richter et al., 2007; vom Saal and Hughes 2005). A small number of researches have been accomplished the effect of BPA ingested orally via BPA-containing food or drinking water. Some of these studies have shown inhibitory effects of BPA on male reproduction, including Leydig cell proliferation and steroidogenesis (Nanjappa et al., 2012), while others have suggested no BPA-induced reproductive abnormalities (LaRocca et al., 2011). Thus, there are discrepancies among the results of BPA-related researches, depending on method, doses, and even experimental model of BPA treatment.

Transgenerational effects of environmental factors on epigenetic inheritance have been examined from several researches. Perinatal oral exposure to BPA at environmentally relevant doses induces decreases of litter size, sperm count, and sperm motility in the male offspring (Salian et al., 2009). Ingestional BPA treatment for three generations results in an increase of spermatogenic cell apoptosis (Manikkam et al., 20120). However, Tyl et al. (2008) have demonstrated no significantly considerable transgenerational effect of dietary BPA on reproductive organ weight or histopathology, including the testis. In addition, exposure to BPA at relatively low doses during gestation doesn't influence on offspring's epididymal sperm count and testis weight (Howdeshell et al., 2008). Together, these inconsistent results indicate no conclusive transgenerational effect of orally exposed BPA on male reproductive tract.

Functions and development of the excurrent ducts of male reproductive tract are regulated by a number of intrinsic and/or extrinsic testicular factors. The effect of estrogen on regulation of fluid reabsorption in the efferent ductules (ED) has been demonstrated from several researches (Lee et al., 2001). Regulation of fluid reabsorption in the ED by estrogen is mediated by differential expressional control of ion transporters (Lee et al., 2001). Even though most of the testicular fluid is reabsorbed in the ED, fluid reabsorption occurs in the epididymis, especially in the head of epididymis (Clulow et al., 1998). Several researches have shown the presence of aquaporin (AQP) isoforms, water channel molecules, in the ED and initial segment (IS). AQP1 and 9 are localized at apical compartment of the ED and IS epithelia (Badran \& Hermo, 2002). Expression of AQP9 in the IS is regulated by testicular factor(s), not androgen (Badran \& Hermo, 2002). Picciarelli- Lima et al. (2006) have shown that estrogenic metabolite could influence expression of AQP9 in the ED. Differential regulation of AQP1 and 9 in the ED and IS by estrogen has been reported by Oliveria et al. (2005). These findings suggest that expression of fluid reabsorption- relating molecules in the ED and IS could be modulated by estrogenic environmental toxicants, such as BPA.

Even though previous researches have suggested harmful effect of BPA on the testis, there is little information available on influence of BPA on the fluid reabsorption in the ED and epididymis. Thus, the present study was designed to find out the transgenerational effects of BPA on expression of ion transporters and AQPs in the mouse ED and IS. Expressional changes of ion transporters and AQPs were determined by relative real-time polymerase chain reactions. The findings from the current research would provide information about possible influence of BPA on the fluid reabsorption of the ED and IS.

\section{MATERIALS AND METHODS}

\section{Experimental animals and BPA treatment}


Twelve male and twelve female ICR mice at 3 months of age were purchased from Samtako (O San, S. Korea) and randomly divided into 4 experimental groups, control, low, medium, or high-dose treatment group. Each group had 3 male and 3 female mice. Each animal was individually caged, and free access to food and drinking water were permitted to animals.

To prepare bisphenol A (BPA, Sigma, St. Louis, USA) containing drinking water, BPA was completely dissolved in $100 \% \mathrm{EtOH}$, and then diluted to $100 \mathrm{ng}$ (low, equivalent to $0.1 \mathrm{ppm}$ ), 10 (medium, equivalent to $10 \mathrm{ppm}$ ), and $1 \mathrm{mg}$ (high, equivalent to 1,000 ppm)/ of final concentrations by adding drinking water. These doses were ranged between the lowest does reporting BPA effect in the literature to the highest dose producing systematic toxicity (Tyl et al., 2008). Fresh BPA-containing drinking water was prepared every other day. Glass water bottles were used to prevent criticism of experimental misconduct by use of BPA-containing plastic bottles. Animal was supplied with BPA-containing drinking water at designed doses for 1 month. Then, a pair of male and female mice of same experimental group was permitted for mating. These pairs of animals were considered as F0 generation. Continuing a supply of BPA-containing water for entire experimental period, F1 generation was obtained from pregnant F0 female mice. Pairs of F1 male and female mice of same experimental group were allowed for mating to get F2 generation.

\section{Tissue collection and total RNA isolation}

When F2 male mice reached 3 months of age, the animals were anesthetized by $\mathrm{CO}_{2}$ stunning. An incision was made on lower abdominal area, and the testis and epididymis were exposed. The epididymal fat covering the efferent ductile (ED) was carefully dissected out in cold PBS, and the ED was separated from the testis and epididymis. The initial segment (IS) was separated from the head of epididymis. Tissues were quickly frozen in liquid nitrogen and stored in $-80^{\circ} \mathrm{C}$ for total RNA isolation. Because the ED or IS collected from a mouse was too small to collect enough amount of total RNA for relative real-time polymerase chain reaction (PCR), each tissue obtained from animals of same experimental group was pooled. At least, 10 male mice of F2 generation for each experimental group were used for the present study.

Frozen tissues were homogenized in easy-Blue total RNA extraction solution (iNtRON Biotech, Sungnam, S. Korea) with a polytron homogenizer (Fisher Scientific, Pittsburgh, PA). Applying phenol-c chloroform extraction method, total RNA was isolated and resuspended in RNA storage buffer (Ambion, Austin, TX). Quantitative and qualitative analyses of total RNA were carried out with an UV spectrophotometer (Eppendorf, New York, USA) and gel electrophoresis, respectively. Total RNA was either directly used for complementary DNA (cDNA) generation or stored in $-80^{\circ} \mathrm{C}$.

\section{Generation of CDNA and relative real-time PCR} analysis

One microgram of total RNA was used to generate cDNA using ImProm-II ${ }^{\mathrm{TM}}$ reverse transcription system (Promega, Madison, USA). The reverse transcription (RT) reaction was carried out with oligo-dT primer. The RT reaction was performed at $25^{\circ} \mathrm{C}$ for $5 \mathrm{~min}, 42^{\circ} \mathrm{C}$ for $1 \mathrm{hr}$ and 30 min, and $70^{\circ} \mathrm{C}$ for $15 \mathrm{~min}$. The cDNA was directly utilized for relative real-time PCR. In the present study, relative real-time PCR was employed to determine BPA-induced expressional changes of 5 ion transporter and 2 aquaporin genes, including carbonic anhydrase II (CAII, Car2), $\mathrm{Na}^{+} /$ $\mathrm{H}^{+}$exchanger 3 (NHE3, Slc9a3), cystic fibrosis transmembrane regulator (CFTR, Cftr), $\mathrm{Na}^{+} / \mathrm{K}^{+}$ATPase $\alpha 1$ subunit (ATPase, Atp1a1), aquaporin (AQP, Aqp) 1, and AQP9. Table 1 shows information of oligonucleotide primers used for real-time PCR analysis.

The real-time PCR was carried out in a mixture of 1 of cDNA, 10 pmol of primer set, 10 of master mixture (Finnzymes, Espoo, Finland), and water to make a final volume of 20 . The PCR mixture was pre-denatured at $95^{\circ} \mathrm{C}$ for $5 \mathrm{~min}$, and the PCR procedure was followed by cycles of denaturation at $95^{\circ} \mathrm{C}$ for $30 \mathrm{sec}$, annealing at $\mathrm{T}_{\mathrm{m}}$ for 
Table 1. List of oligonucleotide primers utilized for real-time PCR analysis

\begin{tabular}{|c|c|c|c|}
\hline Gene & Primer sequence (5’ $\rightarrow 3^{\prime}$ ) & $\operatorname{Tm}\left({ }^{\circ} \mathrm{C}\right)$ & PCR product size (bps) \\
\hline $\begin{array}{l}\text { CAII (Car2) } \\
\text { (K00811.1) }\end{array}$ & $\begin{array}{l}\text { (F) CTCTCAGGACAATGCAGTGC } \\
\text { (R) ATCCAGGTCACACATTCCAG }\end{array}$ & 56 & 391 \\
\hline $\begin{array}{c}\text { NHE3 (Slc9a3) } \\
(\text { NM_001081060.1) }\end{array}$ & $\begin{array}{l}\text { (F) CCACACACTGCAACAGTACC } \\
\text { (R) ATAGGCAGTTTCCCATTAGG }\end{array}$ & 53 & 252 \\
\hline $\begin{array}{c}C f t r \\
(\mathrm{M} 69298.1)\end{array}$ & $\begin{array}{l}\text { (F) CATCTTTGGTGTTTCCTATGATG } \\
\text { (R) GTAAGGTCTCAGTTAGAATTGAA }\end{array}$ & 58 & 418 \\
\hline $\begin{array}{l}\text { ATPase (Atp1a1) } \\
\text { (NM_144900.2) }\end{array}$ & $\begin{array}{l}\text { (F) TCCAGCAGGGAATGAAGAAC } \\
\text { (R) AAGGCACAGAACCACCATGT }\end{array}$ & 55 & 142 \\
\hline $\begin{array}{c}\text { Aqp1 } \\
\left(\mathrm{NM} \_007472.2\right)\end{array}$ & $\begin{array}{l}\text { (F) TAAAGTGGCAAGGAAGGGACAG } \\
\text { (R) CTGGAGGACCGAAATAAACATC }\end{array}$ & 60 & 339 \\
\hline $\begin{array}{c}\text { Aqp9 } \\
(\mathrm{BC} 024105.1)\end{array}$ & $\begin{array}{l}\text { (F) CCTTCTGAGAAGGACCGAGCC } \\
\text { (R) CTTGAACCACTCCATCCTTCC }\end{array}$ & 60 & 300 \\
\hline $\begin{array}{c}\text { Gapdh } \\
\text { (NM_008084.2) }\end{array}$ & $\begin{array}{l}\text { (F) GACCACAGTCCATGACATCACTGC } \\
\text { (R) GCTGTTGAAGTCGCAGGAGACAAC }\end{array}$ & 53 & 340 \\
\hline
\end{tabular}

CAII (Car2) : carbonic anhydrase II; NHE3 (Slc9a3) : $\mathrm{Na}^{+} / \mathrm{H}^{+}$exchanger 3; Cftr : cystic fibrosis transmembrane regulator; ATPase (Atp1a1) : $\mathrm{Na}^{+} / \mathrm{K}^{+}$ATPase $\alpha 1$ subunit; Aqp : aquaporin; and Gapdh : glyceraldehyde-3-phosphate dehydrogenase.

$30 \mathrm{sec}$, and extension at $72^{\circ} \mathrm{C}$ for $30 \mathrm{sec}$. An additional extension step at $72^{\circ} \mathrm{C}$ for 10 min was added at the end of PCR. Glyceraldehyde-3-phosphate dehydrogenase (Gapdh) was used as a PCR internal quantitative control. The sizes of all PCR products were confirmed by agarose gel electrophoresis.

\section{Data presentation and statistical analysis}

Independent quadruplicated RT reactions and PCR were conducted to obtain a mean and a standard error for each experimental group. Expression levels of target molecules were normalized to those of Gapdh, and results are present in relative ratios of expression between Gapdh and target molecule. Statistical significances of expression levels among experimental groups were determined by one-way ANOVA, followed by Duncan' test, a post-hoc analysis. When $\mathrm{P}$ value was lower than 0.05 , it is considered as statistically significant.

\section{RESULTS}

1. Gene expression of CAIl, NHE3, CFTR, and ATPase in the efferent ductules treated with BPAcontaining drinking water for two generations
The BPA treatment resulted in expressional change of CAII gene in the efferent ductules (Fig. 1a). The expression
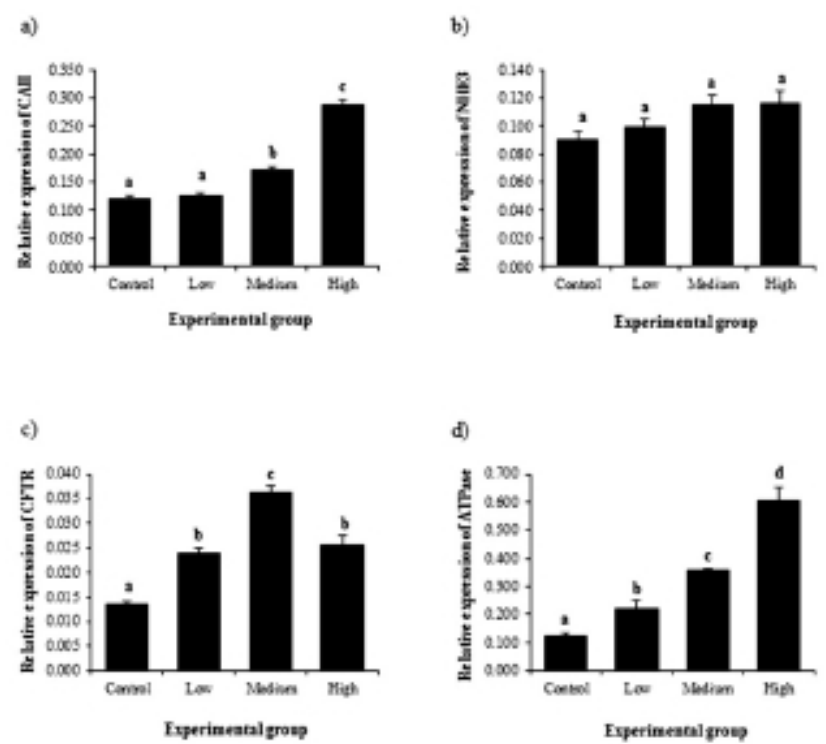

Fig. 1. Effect of BPA administration through drinking water for two generations on expression of ion producer and transporter genes in the efferent ductules of mouse. Animals were treated with drinking water containing no BPA (control), $100 \mathrm{ng}$ (low), 10 (medium), and $1 \mathrm{mg} /$ water (high). Expressional changes of CAII (a), NHE3 (b), CFTR (c), and ATPase (d) genes are shown. Different letters indicate statistically significant differences at $p<0.05$ level. 
of CAII gene was significantly increased by BPA administration at medium dose, and further increase of CAII gene was detected in a BPA treatment at high dose (Fig. 1a). Expression of NHE3 gene was not affected by BPA treatment (Fig. 1b). The treatment of BPA at low dose caused a significant increase of CFTR gene expression (Fig. 1c). The transcript level of CFTR was significantly increased by the treatment of BPA at medium dose, followed by a transient decrease of CFTR gene expression at a high-dose BPA treated group (Fig. 1c). The BPA treatment at low dose resulted in a significant increase of ATPase gene expression (Fig. 1d). Additional increases of ATPase gene expression were detected in the efferent ductules treated with BPA at medium and high doses (Fig. 1d).

\section{Gene expression of AQP1 and AQP9 in the} efferent ductules treated with BPA-containing drinking water for two generations

Expressional changes of AQP genes by BPA treatment are shown in Fig. 2. The treatment of BPA at low dose caused a significant increase of AQP1 gene (Fig. 2a). An additional increase of AQP1 gene expression was detected at medium-dose BPA treatment (Fig. 2a). However, the treatment of BPA at high dose did not result in further expressional change of AQP1 (Fig. 2a). Gene expression of AQP9 was only influenced by BPA treatment at medium dose, while other BPA treatment didn't affect expression
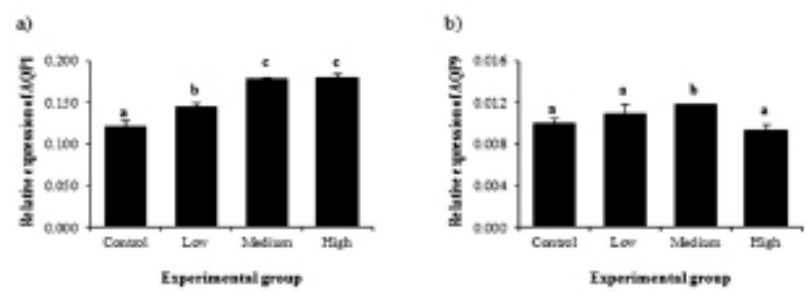

Fig. 2. Effect of BPA administration through drinking water for two generations on expression of aquaporin genes in the efferent ductules of mouse. Animals were treated with drinking water containing no BPA (control), 100 ng (low), 10 (medium), and $1 \mathrm{mg}$ water (high). Expressional changes of AQP1 (a) and AQP9 (b) genes are shown. Different letters indicate statistically significant differences at $p<0.05$ level. of AQP9 gene (Fig. 2b).

3. Gene expression of CAll, NHE3, CFTR, and ATPase in the initial segment treated with BPA-containing drinking water for two generations

Expression of CAII in the initial segment was significantly increased by BPA treatment at medium dose, followed by a decrease of CAII transcript level in high-dose BPA treated group (Fig. 3a). Treatments of BPA at low and high doses resulted in decreases of NHE3 gene expression, while expression of NHE3 gene was significantly increased by medium-dose BPA treatment (Fig. 3b). A change of CFTR transcript level was first detected at low-dose BPA treated group (Fig. 3c). BPA treatment at medium dose caused another increase of CFTR gene expression (Fig. 3c). However, high-dose BPA treatment didn’t give an influence on expressional change of CFTR gene (Fig. 3c). Expressional pattern of ATPase by BPA treatment was similar with that of CFTR (Fig. 3d). Expression of
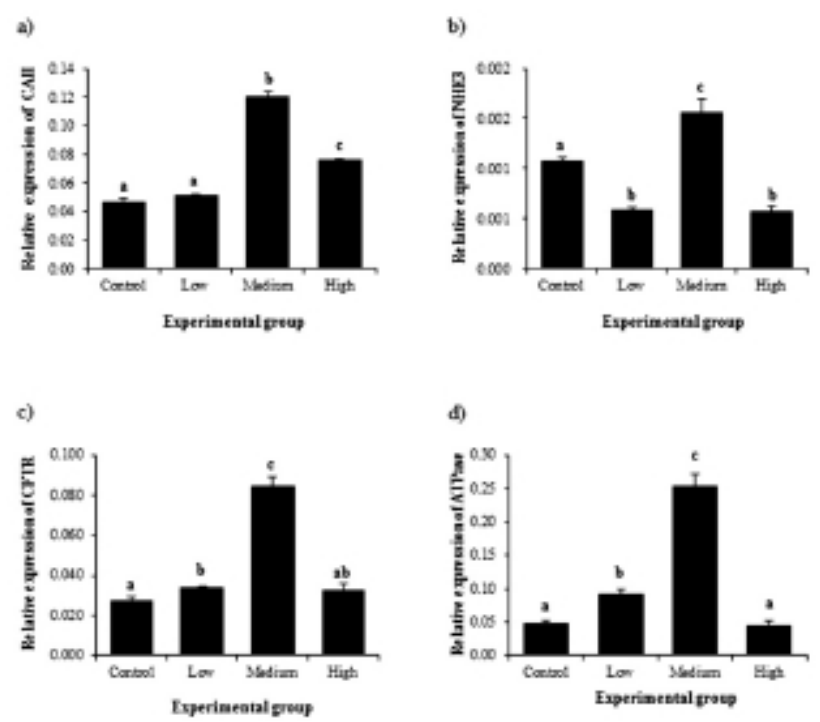

Fig. 3. Effect of BPA administration through drinking water for two generations on expression of ion producer and transporter genes in the initial segment of mouse. Animals were treated with drinking water containing no BPA (control), $100 \mathrm{ng}$ (low), 10 (medium), and $1 \mathrm{mg}$ water (high). Expressional changes of CAII (a), NHE3 (b), CFTR (c), and ATPase (d) genes are shown. Different letters indicate statistically significant differences at $p<0.05$ level. 
ATPase gene was significantly increased by low-dose BPA treatment (Fig. 3d). Additional increase of ATPase transcript level was found at medium-dose BPA treated group, even though BPA treatment at high dose didn't cause a change of ATPase gene expression (Fig. 3d).

\section{Gene expression of AQP1 and AQP9 in the initial} segment treated with BPA-containing drinking water for two generations

Transcript levels of AQP1 became significantly increased with low-dose BPA treatment (Fig. 4a). BPA treatment at medium dose led into additional increase of AQP1 gene expression (Fig. 4a). However, treatment of BPA at high dose didn't show expressional change of AQP1 gene, compared to that of control (Fig. 4a). In case of AQP9, a significant change of transcript level was only detected in medium-dose BPA treated group, while BPA treatment at other doses didn't result in change of AQP9 gene expression (Fig. 4b).

\section{DISCUSSION}

The most common route to be exposed to BPA is oral intake of BPA-containing food and/or drink. Thus, ingestion of BPA via drinking source is one of most realistic methods to examine the effect of BPA in experimental animal. Results from the present research showed a possibility
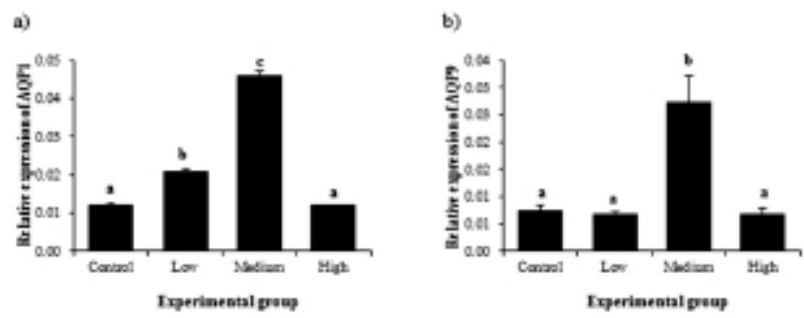

Fig. 4. Effect of BPA administration through drinking water for two generations on expression of aquaporin genes in the initial segment of mouse. Animals were treated with drinking water containing no BPA (control), 100 ng (low), 10 (medium), and $1 \mathrm{mg} /$ water (high). Expressional changes of AQP1 (a) and AQP9 (b) genes are shown. Different letters indicate statistically significant differences at $p<0.05$ level. of transgenerational detrimental effect of BPA on fluid reabsorptive function of the ED and IS. Expression of ion transporters and AQPs in the ED and IS was differentially affected by BPA treatment for two generations. In the ED, except NHE3 and AQP9, it is generally stated that expression of ion transporters and AQP1 is increased along with a rise of BPA dose. Interestingly, treatment with 10 of BPA/ water resulted in increases of gene expression of all molecules in the IS. In most of cases, the highest dose of BPA treatment didn't give any change of genes expression.

Information about the effect of BPA on the ED is not available yet. A number of researches have shown expressional regulation of ion transporters and AQPs by estrogen in the ED. Lee et al. (2001) have demonstrated that loss of estrogen receptor $\alpha(\mathrm{ER} \alpha)$ gives an influence on gene expression of CAII, NHE3, CFTR, and ATPase. Disruption of estrogen effect in the ED by loss of ER $\alpha$ or antiestrogen treatment results in a decrease of CAII gene expression and increases of CFTR and ATPase gene expression (Lee et al., 2001). These findings are in agreement with expression changes of CFTR and ATPase by BPA treatment found in the present research. It is considered that expression of CFTR and ATPase genes in the ED is likely under regulation of estrogen and/or estrogenic components. Our present findings suggest that ingestion of BPA-containing water for two generations is probably sufficient to modulate expression of ion transporters involving in fluid reabsorption in the ED. A bulk of testicular fluid reabsorption in the ED is essential for proper sperm maturation in the epididymis (Turner, 1984). Thus, BPA-induced alternation of expression of ion transporter genes in the ED could affect the male fertility. Mating study with F2 generation progeny in a large scale is suggested to determine a relationship between long-term exposure to BPA and male fertility.

Treatment of antiestrogen leads to a decrease of AQP9, not AQP1, expression in the ED, indicating estrogenmediated AQP9 expression in the ED (Oliveira et al., 2005). Expression of AQP9 in the ED is regulated by 
3-betal-diol, an androgen metabolite with estrogenic property (Picciarelli-Lima et al., 2006). However, results from the present study showed an increase of AQP1 gene expression at high doses, while AQP9 gene expression is increased at only 10 of BPA/ dose. The discrepancy between previous and current results implies that BPA and estrogen would act on the ED in a different way even though the action of BPA is known to be mediated via ER. It is also possible that long-term exposure to a weak estrogenic compound, such as BPA, would lead to epigenetic modification of AQP genes in the ED. This would produce different results with acute treatment of estrogen for relatively short period.

A few researches have conducted to determine the effect of BPA exposure on the epididymis. A decrease of epididymal weight is found with subcutaneous or intraperitoneal BPA injection (Takahashi \& Oishi, 2003). However, others have shown no significant effect of BPA exposure on the epididymis (Cagen et al., 1999). Such discrepancy among researches would be due to differences of treatment, animal model, and dose of BPA. Even though these researches have attempted to show the effect of BPA on the epididymis, their efforts have been restricted into examination of gross change in the epididymis. To date, there is no research conducted to determine the effect of BPA on function of the epididymis. To our knowledge, our present study is the first effort to investigate consequence of BPA exposure in the IS. Expression changes of ion transporters and AQPs in the IS by BPA treatment were clearly different from those in the ED. It is noteworthy to pay a note on the highest increases of gene expression at 10 of BPA/ dose, not $1 \mathrm{mg}$ of BPA/ . Kendig et al. (2012) have reported that dietary treatment of BPA at lower doses, not higher dose, results in alterations of circulating testosterone levels and sperm counts. Even though evidence is not available to explain such paradoxical effect of BPA shown at higher dose, suppression of gene expression by high-dose BPA in indirect ways would be one of possible answers. Together, these findings suggest that exposure to BPA would not always produce the effects in dose-dependent manner. There is no conclusive information available on the effect of BPA on the functions of the epididymis. Detailed molecular approaches should be carried out to inspect transgenerational effects of BPA on the epididymis.

Transgenerational effects of environmental endocrine disrupters, including BPA, have been examined by several researches. A research shows unfavorable consequences in immune organs, such as spleens, after BPA exposure for two generations (Miao et al., 2008). However, others have exhibited no significant effect on the male reproductive tract with exposure to BPA for two generations (Tyl et al., 2008). The findings from our present study indicate a possible transgenerational effect of BPA on the ED and IS. There is no clear answer to explain the inconsistency among experiments. However, it is reasonable to consider that different doses and/or methods of treatments could cause the disagreement of experimental results. In addition, the use of different animal models would produce conflicting outcomes on the effect of BPA exposure. Indeed, there is a number of evidence demonstrating genetic variation of experimental animals in susceptibility to estrogen (Spearow et al., 1999). Therefore, to resolve transgenerational effects of BPA on the male reproductive tract, more careful management of experiments is required to avoid false positive and/or negative results.

\section{ACK NOWLEDGEMENTS}

This research was partly supported by Basic Science Research Program through the National Research Foundation of Korea (NRF) funded by the Ministry of Education, Science and Technology (20080060640 and 20100022388).

\section{REFERENCES}

Alonso-Magdalena P, Ropero AB, Soriano S, GarcíaArévalo M, Ripoll C, Fuentes E, Quesada I, Nadal Á (2012) Bisphenol-A acts as a potent estrogen via nonclassical estrogen triggered pathways. Mol Cell Endocrinol 
355:201-207.

Cagen SZ, Waechter JM Jr, Dimond SS, Breslin WJ, Butala JH, Jekat FW, Joiner RL, Shiotsuka RN, Veenstra GE, Harris LR (1999) Normal reproductive organ development in Winstar rats exposed to bisphenol A in the drinking water. Regul Toxicol Pharmacol 30: 130-139.

Clulow J, Jones RC, Hansen LA, Man SY (1998) Fluid and electrolyte reabsorption in the ductuli efferentes testis. J Reprod Fertil Suppl 53:1-14.

Gupta MS (2000) Reproductive malformation of the male offspring following maternal exposure to estrogenic chemicals. Proc Soc Exp Biol. Med 224:61-68.

Howdeshell KL, Furr J, Lambright CR, Wilson VS, Ryan BC, Gray LE Jr (2008) Gestational and lactational exposure to ethinyl estradiol, but not bisphenol A, decreases androgen-dependent reproductive organ weights and epididymal sperm abundance in the male long evans hooded rat. Toxicol Sci 203:371-382.

Kendig EL, Buesing DR, Christie SM, Cookman CJ, Gear RB, Hugo ER, Kasper SN, Kendziorski JA, Ungi KR, Williams K, Belcher SM (2012) Estrogen-like disruptive effects of dietary exposure to bisphenol A or 17a-ethinyl estradiol in CD1 mice. Int $\mathrm{J}$ Toxicol 31:537-550.

LaRocca J, Boyajian A, Brown C, Smith SD, Hixon M (2011) Effects of in utero exposure to Bisphenol A or diethylstilbestrol on the adult male reproductive system. Birth Defects Res B Dev Reprod Toxicol 92:526-533.

Lee KH, Finnigan-Bunick C, Bahr J, Bunick D (2001). Estrogen regulation of ion transporter messenger RNA levels in mouse efferent ductules are mediated differentially through estrogen receptor (ER) alpha and ER beta. Biol Reprod 65:1534-1541.

Manikkam M, Guerrero-Bosagna C, Tracey R, Haque MM, Skinner MK (2012) Transgenerational actions of environmental compounds on reproductive disease and identification of epigenetic biomarkers of ancestral exposures. PLoS One 7:e31901.

Miao S, Gao Z, Kou Z, Xu G, Su C, Liu N (2008) Influence of bisphenol A on developing rat estrogen receptors and some cytokines in rats: a two-generational study. J Toxicol Environ Health A 71:1000-1008.

Nanjappa MK, Simon L, Akingbemi BT (2012) The industrial chemical bisphenol A (BPA) interferes with proliferative activity and development of steroidogenic capacity in rat Leydig cells. Biol Reprod 86:1-12.

Oliveira CA, Carnes K, França LR, Hermo L, Hess RA (2005) Aquaporin-1 and -9 are differentially regulated by oestrogen in the efferent ductile epithelium and initial segment of the epididymis. Biol Cell 97:385-395.

Picciarelli-Lima P, Oliveira AG, Reis AM, Kalapothakis E, Mahecha GAB, Hess RA, Oliveira CA (2006) Effect of 3-beta-diol, an androgen metabolite with intrinsic estrogen-like effects, in modulating the aquaporin-9 expression in the rat efferent ductules. Reporod Biol Endocrinol 4:51.

Richter CA, Bimbaum LS, Farabollini F, Newbold RR, Rubin BS, Talsness CE, Vandenbergh JG, Walser-Kuntz DR, Vom Saal FS (2007) In vivo effects of bisphenol A in laboratory rodent studies. Reprod Toxicol 24:199224.

Rubin BS (2011) Bisphenol A : an endocrine disrupter with widespread exposure and multiple effects. J Steroid Biochem Mol Biol 127:27-34.

Salian S, Doshi T, Vanage G (2009) Perinatal exposure of rats to Bisphenol A affects the fertility of male offspring. Life Sce 85:742-752.

Sheeler CQ, Dudley, MW, Khan SA (2000) Envrionmental estrogens induce transcriptionally active estrogen receptor dimmers in yeast: activity potentiated by the coactivator RIP140. Environ Perspect 108:97-103.

Spearow JL, Doemeny P, Sera R, Leffler R, Barkley M (1999) Genetic variation in susceptibility to endocrine disruption by estrogen in mice. Science 285:1259-1261.

Takahashi O, Oishi S (2003) Testicular toxicity of dietarily or parenterally administrated bisphenol A in rats and mice. Food Chem Toxicol 41:1035-1044.

Turner TT (1984) Resorption versus secretion in the rat epididymis. J Reprod Fertil 72:509-514. 
Tyl RW, Myers CB, Marr MC, Sloan CS, Castillo NP, Veselica MM, Seely JC, Dimond SS, van Miller JP, Shiotsuk RN, Beyer D, Hentges SG, Waechter JM (2008) Two-generation reproductive toxicity study of dietary bisphenol A in CD-1 (Swiss) mice. Toxicol Sci 104:362-384.

Vanderberg LN, Chauhoud I, Heindel JJ, Padmanabhan V, Paumgartten FJ, Schoenfelder G (2010) Urinary, circulating and tissue biomonitoring studies indicate widespread exposure to bisphenol A. Environ Health Perspect 118:1055-1070.

vom Saal FS, Cooke PS, Buchanan DL, Palanza P, Thayer KA, Nagel SC, Parmigiani S, Welshons WV (1998) A physiologically based approach to the study of bisphenol $\mathrm{A}$ and other estrogenic chemicals on the size of reproductive organs, daily sperm production, and behavior. Toxicol Ind Health 14:2390260.

vom Saal FS, Hughes C (2005) An extensive new literature concerning low-dose effects of bisphenol A shows the need for a new risk assessment. Environ Health Perspect 113:926-933.

Welshones WV, Nagel SC, vom Saal FS (2006) Large effects from small exposures, III. Endocrine mechanisms mediating effects of bisphenol A at levels of human exposure. Endocrinology 147:S56-S69.

Wong EWP, Cheng CY (2011) Impacts of environmental toxicants on male reproductive dysfunction. Trends Pharmacol Sci 32:290-299. 